
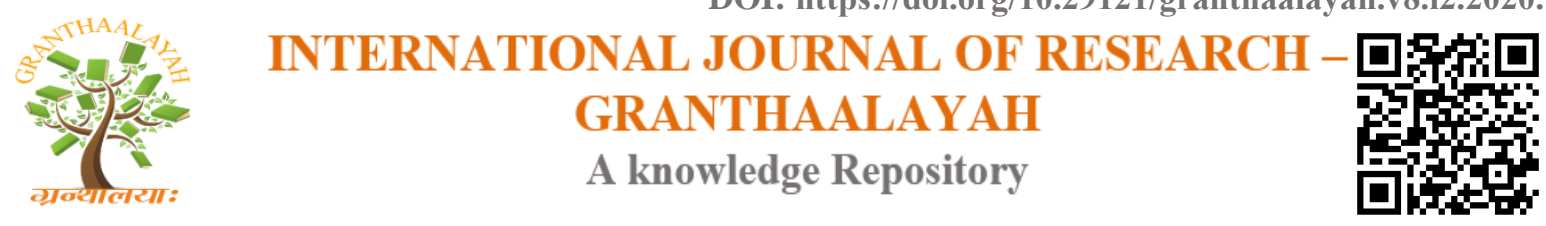

Social

\title{
COMPARING MODELS OF ACCREDITATION AND ACADEMIC PERFORMANCE RELATIONSHIP USING GENERALIZED STRUCTURAL COMPONENT ANAL YSIS
}

\author{
Budi Susetyo *1 \\ ${ }^{* 1}$ Department of Statistics, IPB University, Bogor, Indonesia
}

\begin{abstract}
The National Education Standards Board in Indonesia is an independent and professional institution which maintain and control the quality of education. The National Examination is one of indicator which can be used as a basis for evaluating quality of education. National Accreditation Board for Schools conducts assessment to the schools on fulfillment of the established standards through accreditation process. There are several theoretical models of relationship between 8 national education standards for describing causality each other. The objective of this study are (1) to compare and determine the best model of the relationship between eight standards using generalized structured component analysis; and (2) to evaluate validity of indicators of accreditation instrument. It has been concluded that the model published by the Ministry of Education and Culture (2017) was the best model. AVE and Cronbach's alpha showed that score on Mathematics, Science, English and Indonesian Language are important indicators for academic performance. Critical ratio and variance inflation factor showed that there are 13 of 124 indicators of accreditation instrument are not valid. Analysis of structural model showed that school management has a big influence on standard of teachers and education staff. In addition, curriculum, standard of competency, standard of assessment and standard of process have direct influences to academic achievement.
\end{abstract}

Keywords: Generalized Structured Component Analysis; National Education Standard; National Examination.

Cite This Article: Budi Susetyo. (2020). "COMPARING MODELS OF ACCREDITATION AND ACADEMIC PERFORMANCE RELATIONSHIP USING GENERALIZED STRUCTURAL COMPONENT ANALYSIS." International Journal of Research - Granthaalayah, 8(2), 63-71. https://doi.org/10.29121/granthaalayah.v8.i2.2020.185.

\section{Introduction}

Education influences various aspects of life. With rapid changing of technologies in almost all aspect of life, education system needs to prepare students to think using higher order skills. The goal of education is not only for expanding the access, but also for improving the quality of 
education through developing curriculum, learning process, infrastructure, management, teachers etc. Although since early 2000s, education spending in Indonesia has increased dramatically, but the quality of education is still left behind from many other counties in the world.

The National Education Standards Board (BSNP) as an independent and professional institution in Indonesia which has the task to maintain and control the quality of education. BSNP prepares and develops the National Education Standards (NES) as a basis for planning, implementing, and monitoring education in order to realize quality national education.

Based on regulation, definition of NES is a minimum criteria that has to be fulfilled by schools. NES consists of eight standards, namely standard of content (SI), standard of process (SPR), standard of competency (SKL), standard of teachers and education staff (SPT), standard of infrastructure (SSP), standard of management (SPL), standard of budget (SB), and standard of assessment (SPN).

The National Accreditation Board for Schools and Madrasah (BAN-S/M) conducts assessment to the schools and madrasah on fulfillment of the established standards by BSNP through accreditation process.

Theoretically, fulfillment of SNP can be characterized by relationship between accreditation and achievement of national examination (NE), because the national examination is one of good indicators which can be used as a basis for evaluating of NES achievements. Schools with good accreditation are expected to have a good NE score.

Eight standards in the NES are used as a basis for developing of accreditation instrument. The eight NES are latent variables that cannot be measured directly. The eight SNP assessments were measured by 124 indicators for junior secondary education level. There are several theories that explain the relationship between eight SNP that have been published, namely the Ministry of National Education and Ministry of Religion (2010), the Ministry of National Education and Culture (2012), and the Ministry of National Education and Culture (2017). Few similar studies about relationships between 8 standards have been carried out, for instance Setiawan et al (2018), Hijrah et al (2018) and Vita et al (2015).

Structural equation modeling (SEM) is one of the popular statistical method for identifying the relationship between factors and to evaluate validity of indicators of the factors. In term of model and its parameter estimation, there are two types of SEM approaches, namely covariance based SEM (CBSEM) and variance based SEM (VBSEM). The CBSEM is an ideal approach because it can identify the relationship between latent variables and has an overall goodness of fit model. However, CBSEM requires assumptions of a large number of sample size, multivariate normal distribution and the relationship between latent variable and the indicators should be reflective (Hwang dan Takane (2014). VBSEM was developed to overcome the limitations of CBSEM. In VBSEM, there are three approaches of parameter estimation, namely partial least square path modelling (PLSPM), generalized structural component analysis (GSCA) and fuzzy cluster wise generalized structural component analysis (FGSCA). PLSPM does not require assumption of multivariate normal distribution and it can be implemented to nominal and ordinal, but PLSPM doesn't have an overall goodness of fit model. 
Hwang and Takane (2004) developed the GSCA method to overcome limitations on CBSEM and PLSPM in which it does not require multivariate normal distribution but it has overall goodness of fit. This study aims to compare and determine the best model of the three relationship models of 8 education standards and academic achievement in Indonesia using GSCA method.

\section{Materials and Methods}

\section{Data}

The study uses accreditation and national assessment data of junior secondary schools in Indonesia consisting of 2069 data in 2018. Accreditation data consists of 124 observable indicators with scale from 0 to 4 from 8 latent variables, while national examination data consists of exam score of four subjects, namely English (ING), Indonesian Language (BIN), Mathematics (MTK) and Natural Sciences (IPA). Table 1 describes list of latent variables and their corresponding number of each observable indicators.

Table 1: List of latent variables

\begin{tabular}{|l|c|}
\hline Latent & The Number of Indicator \\
\hline Standard of Content (SI) & 9 \\
\hline Standard of Process (SPR) & 21 \\
\hline Standard of Competency (SKL) & 7 \\
\hline Standard of Teacher and Education Staff (SPT) & 19 \\
\hline Standard of Infrastructure (SSP) & 24 \\
\hline Standard of Management (SPL) & 15 \\
\hline Standard of Budget (SB) & 16 \\
\hline Standard of Assessment (SPN) & 13 \\
\hline Academic Achievement (PA) & 4 \\
\hline
\end{tabular}

\section{The Steps of Data Analysis}

The data analysis is conducted with the following steps:

1) Carrying out data exploration by looking at correlation and comparing accreditation status with average of exam score.

2) Building relationship models between 8 standards (NES) and academic performance (PA). This study used model of the Ministry of National Education and The Ministry of Religion (2010), the Ministry of National Education and Culture (2012) and the Ministry of National Education and Culture (2017) as showed in in Figure 1, Figure 2, and Figure 3.

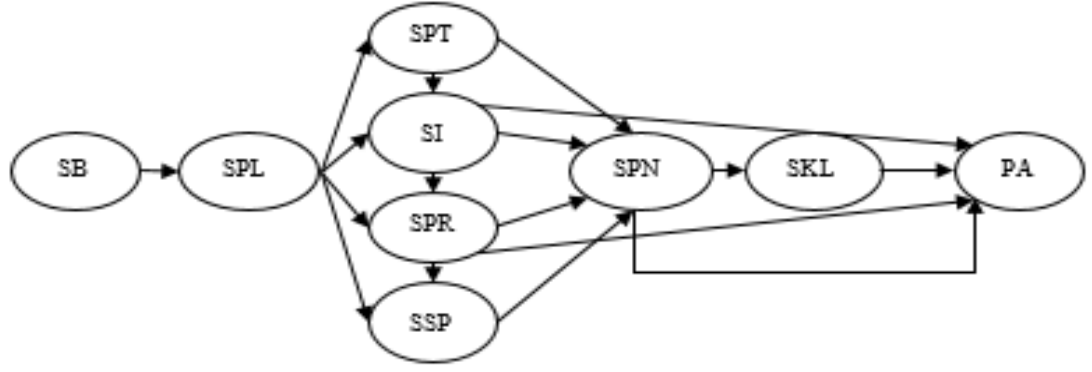

Figure 1: Structural Model of the Ministry of National Education and the Ministry of Religion (2010) 


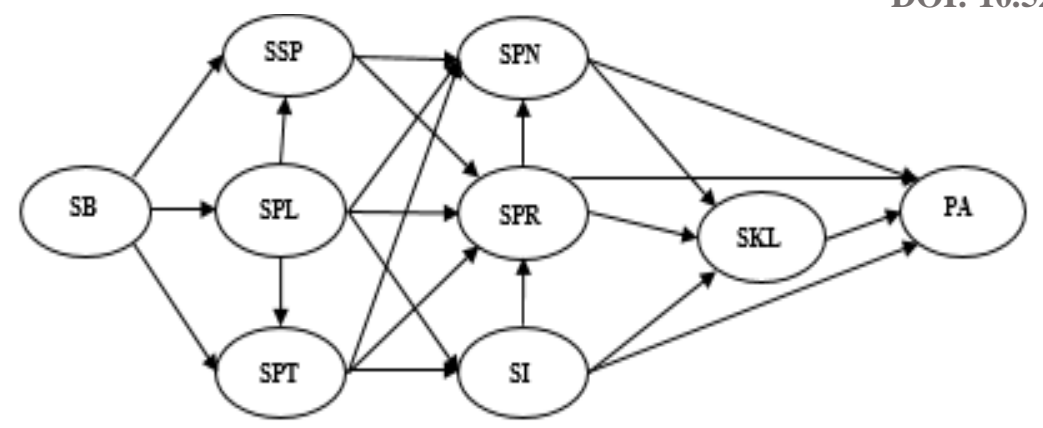

Figure 2: Structural Model of the Ministry of National Education and Culture (2012)

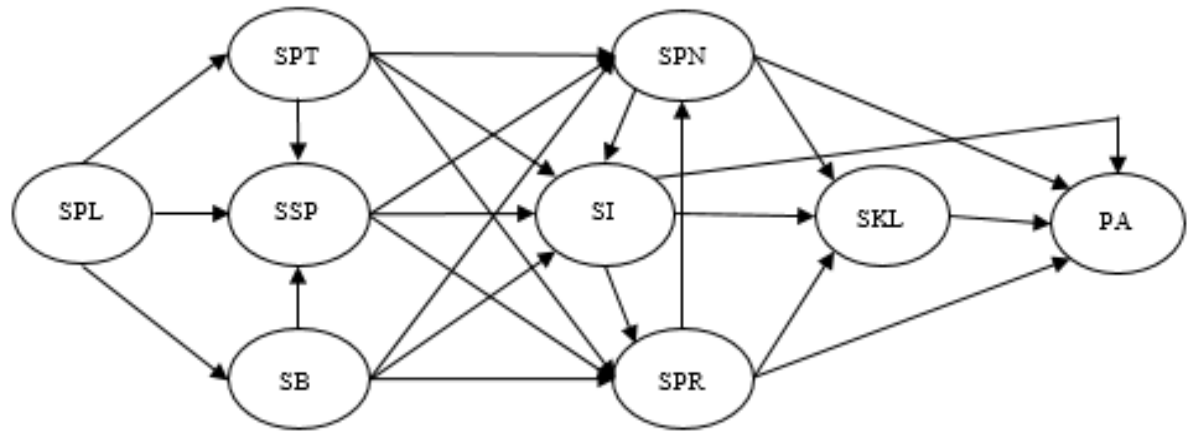

Figure 3: Structural Model of the Ministry of National Education and Culture (2017)

3) Analyzing structural equation models with GSCA through estimating parameters, loading factor estimator, path coefficient estimator, and the standard error of the parameter.

4) Evaluating reflective measurement model on academic achievement (PA)

- Evaluate convergent validity based on value of the loading factor PA.

- Evaluate discriminant validity by comparing the square root of AVE and the correlation between PA and other latent variables in the model. The square root of the AVE of each latent is greater than the correlation value between other latent in the model (Fornell and Lacker 1981). The AVE is obtained using the following formula:

$$
\mathrm{AVE}=\frac{\sum \lambda i^{2}}{\sum \lambda i^{2}+\sum\left(1-\lambda i^{2}\right)}
$$

- Evaluate composite reliability with Cronbach's Alpha. In order to obtain reasonably good reliability, it is recommended that the value of the Cronbach's Alpha value is greater or equal to 0.70 .

5) Evaluating formative measurement model on 8 national education standards by weight significance and multicollinearity tests. The recommended weight significance is more than 1.96. The multicollinearity tests based on variance inflation factor (VIF) values and the VIF value is less than 10 (Hwang Takane 2004).

6) Evaluate structural model by $\mathrm{T}$ statistic test on the parameters of the structural model and coefficient of determination $\left(\mathrm{R}^{2}\right)$.

7) Determine overall goodness of fit model using FIT and AFIT. The FIT and AFIT formulas are as follows (Ryoo 2017): 


$$
\begin{gathered}
F I T=1-\left[\frac{\sum_{i=1}^{N}\left(\boldsymbol{V} \mathbf{z}_{\boldsymbol{i}}-\boldsymbol{A} \boldsymbol{W} \boldsymbol{z}_{\boldsymbol{i}}\right)^{\prime}\left(\boldsymbol{V} \mathbf{z}_{\boldsymbol{i}}-\boldsymbol{A W} \mathbf{z}_{\boldsymbol{i}}\right)}{\sum_{i=1}^{N}\left(\mathbf{z}_{\boldsymbol{i}}^{\prime} \boldsymbol{V}^{\prime} \boldsymbol{V} \mathbf{z}_{\boldsymbol{i}}\right)}\right] \\
A F I T=1-(1-F I T) \frac{d_{0}}{d_{1}}
\end{gathered}
$$

\section{Results and Discussions}

\section{Data Exploration}

The number of observations of accreditation and national examination is 2069 junior education schools consisting of 877 public schools, 867 private schools, 62 public madrasahs and 263 private madrasahs. The overall percentage of school accredited A is $58.48 \%$, accredited B is $35.23 \%$, accredited $\mathrm{C}$ is $6.09 \%$ and not accredited is $0.19 \%$. Based on Table 2, the correlation coefficient between the eight standards and national score shows a fairly high and positive. Figure 3 also shows that schools with better accreditation have higher average exam score in each field of study. Setiawan et al (2018) also concluded that there is a relationship between accreditation status and national examination.

Table 2: Correlation matrix of 8 standards and exam score

\begin{tabular}{|l|l|l|l|l|}
\hline & BIN & ING & MTK & IPA \\
\hline SI & 0.43 & 0.31 & 0.32 & 0.36 \\
\hline SPR & 0.45 & 0.37 & 0.36 & 0.4 \\
\hline SKL & 0.47 & 0.4 & 0.38 & 0.41 \\
\hline SPT & 0.34 & 0.29 & 0.29 & 0.32 \\
\hline SSP & 0.52 & 0.42 & 0.41 & 0.45 \\
\hline SPL & 0.45 & 0.36 & 0.36 & 0.40 \\
\hline SB & 0.36 & 0.27 & 0.27 & 0.30 \\
\hline SPN & 0.42 & 0.36 & 0.35 & 0.38 \\
\hline
\end{tabular}

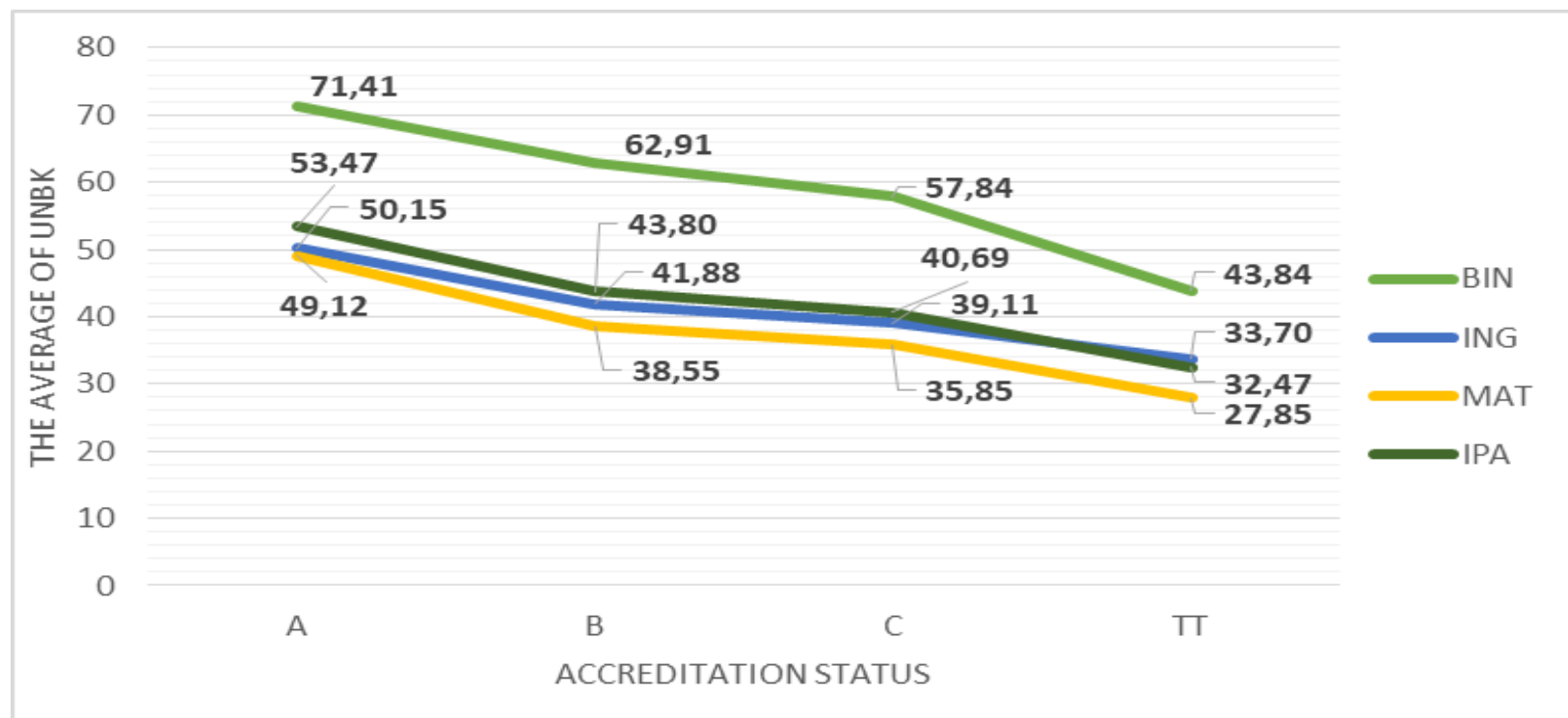

Figure 3: The average of Exam Score based on accreditation status 


\section{Evaluation of Measurement Models}

Evaluation of measurement model with a reflective indicator variable was carried out by assessing the convergent validity, discriminant validity and composite reliability. Based on Table 3 , the value of the loading factor for model 1, model 2 and model 3 in each indicator shows a value greater than 0.70 and significant at the significant level of 5\%. It can be concluded that the indicators for the latent variable of PA have good convergent validity (Hwang and Takane, 2004). Cronbach's alpha shows a value greater than 0.70 which means that the indicator for the latent variable PA has good composite reliability. While the $\sqrt{\mathrm{AVE}}$ value obtained for model 1 , model 2 and model 3 is 0.951 . If the $\sqrt{\mathrm{AVE}}$ value is compared with the correlation between PA and other latent variables in Table 4, then the $\sqrt{\mathbf{A V E}}$ value is greater than the correlation value between PA and other latent variables. This shows that the indicator for the latent variable PA has good discriminant validity.

Evaluation of the measurement model with a formative indicator variable is carried out by assessing the significance of its weight. The evaluation results of model 1 show that there are 14 indicators are not significant, namely 13, 17, 38, 39, 46, 51, 55, 57, 59, 74, 75, 76, 80, and 108 at the significance level of $5 \%$.

Table 3: Loading factor of academic performance

\begin{tabular}{|l|l|l|l|l|l|l|}
\hline \multirow{2}{*}{ Indicator } & \multicolumn{2}{|c|}{ Model 1 } & \multicolumn{2}{c|}{ Model 2 } & \multicolumn{2}{c|}{ Model 3 } \\
\cline { 2 - 7 } & Load. & CR & Load. & CR & Load. & CR \\
\hline BIN & 0.936 & 286.64 & 0.936 & 287.69 & 0.936 & 283.960 \\
\hline ING & 0.942 & 333.30 & 0.942 & 416.22 & 0.942 & 321.670 \\
\hline MAT & 0.956 & 328.36 & 0.957 & 339.17 & 0.957 & 338.020 \\
\hline IPA & 0.969 & 467.64 & 0.969 & 472.10 & 0.969 & 636.310 \\
\hline AVE & 0.905 & 0.905 & 0.905 & \\
\hline$\sqrt{\text { AVE }}$ & 0.951 & 0.951 & 0.951 & \\
\hline ALPHA & 0.961 & 0.961 & 0.961 & \\
\hline
\end{tabular}

Table 4: Correlation value of academic performance with other latent variables

\begin{tabular}{|l|c|c|c|}
\hline Latent & Model 1 & Model 2 & Model 3 \\
\hline SB & 0.37 & 0.37 & 0.37 \\
\hline SPL & 0.45 & 0.45 & 0.45 \\
\hline SPT & 0.44 & 0.50 & 0.44 \\
\hline SI & 0.40 & 0.44 & 0.40 \\
\hline SPR & 0.45 & 0.42 & 0.45 \\
\hline SSP & 0.51 & 0.45 & 0.51 \\
\hline SPNet & 0.42 & 0.40 & 0.42 \\
\hline SKL & 0.46 & 0.46 & 0.46 \\
\hline
\end{tabular}

The evaluation results of model 2 show that 13 indicator are not significant, namely items 13, 38, $39,46,51,55,57,59,72,74,75,80$, and 108. Meanwhile based on Setiawan et al (2018), there are 11 indicators are not significant in model 3 namely items 17, 39, 51, 55, 57, 59, 73, 75, 76, 80 and 108. The indicator variables that are not significant are excluded from the next model and can be used as evaluation by interested parties. In addition, the multicollinearity test is carried out 
based on the VIF value with a recommended value of less than 10. The results of multicollinearity test on each indicators give VIF value less than 10 so that all indicators have met the assumptions of multicollinearity.

\section{Evaluation of Structural Model}

The structural model is evaluated by identify the parameter coefficient and the significance of these parameters. Figure 4 presents a structural model based on the Ministry of National Education and Ministry of Religion (2010) with R-square and coefficients for each path. In the model, the relationship between SI and PA with a path coefficient of 0.012 is not significant. This shows that SI has relationship between PA but does not significantly affect at the significance level of $5 \%$. Figure 5 presents a structural model based on the Ministry of Education and Culture (2012) with the R-square and coefficient of each path. In this model, the relationship between SI and PA and the relationship between SPT and SPN are not significant. This shows that SI has relationship between PA and SPT has relationship between SPN but do not significantly affect at the significance level of 5\%. Meanwhile, Figure 6 presents a structural model based on Ministry of National Education (2017) with R-square and coefficients for each path. In the model, the relationship between SI and PA with a path coefficient of 0.018 is not significant. This shows that SI has relationship between PA but does not significantly affect at the significance level of 5\%.

The latent variables that give direct influence on PA in both models are SKL, SI, SPR and SPN, but the direct influence of SI on PA is not significant. The greatest influence on PA is the SKL. The R-square value of each latent variable in model ranged from $0.200-0.720$. This means that the minimum variant that can be explained in both model is $20 \%$.

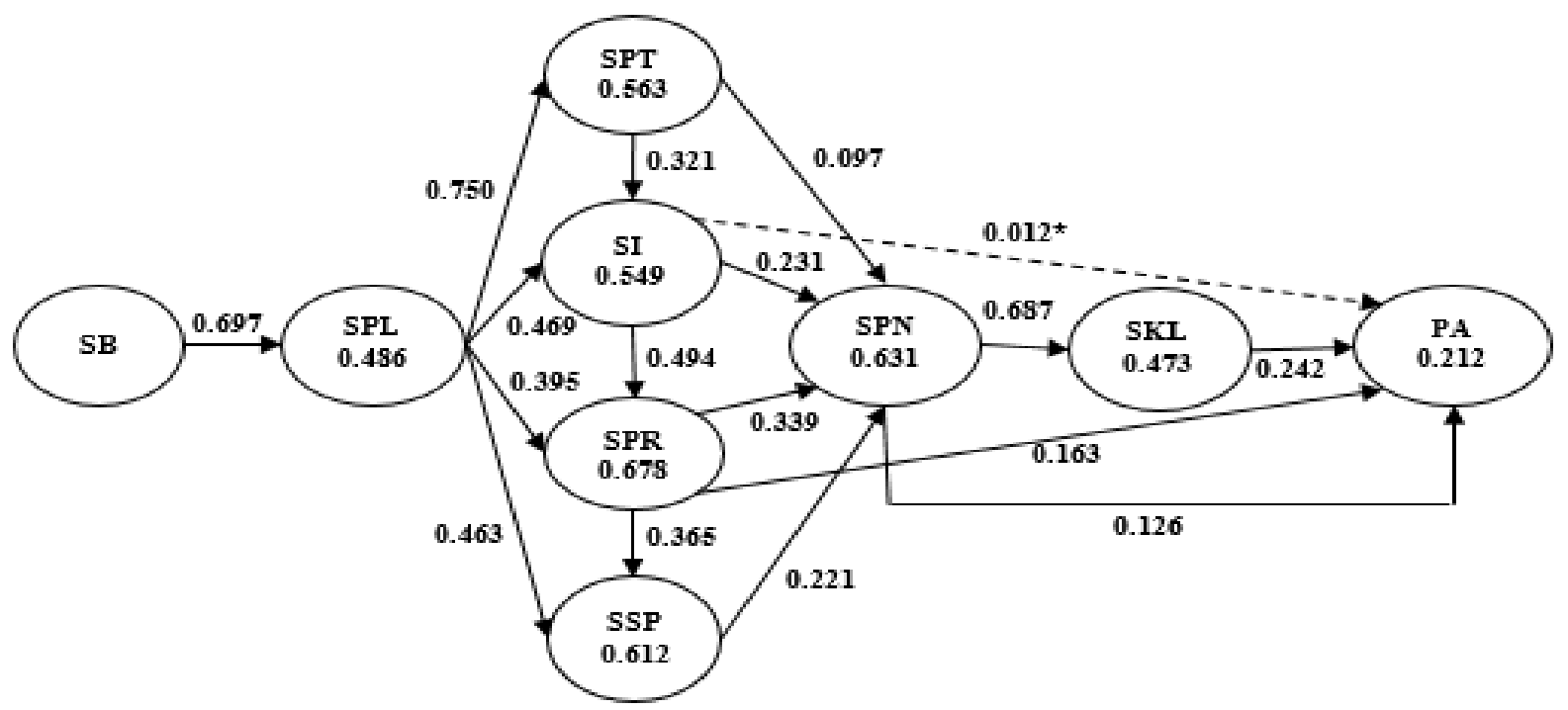

Figure 4: Structural Model 1 Based on the Ministry of National Education and Ministry of Religion (2010) 


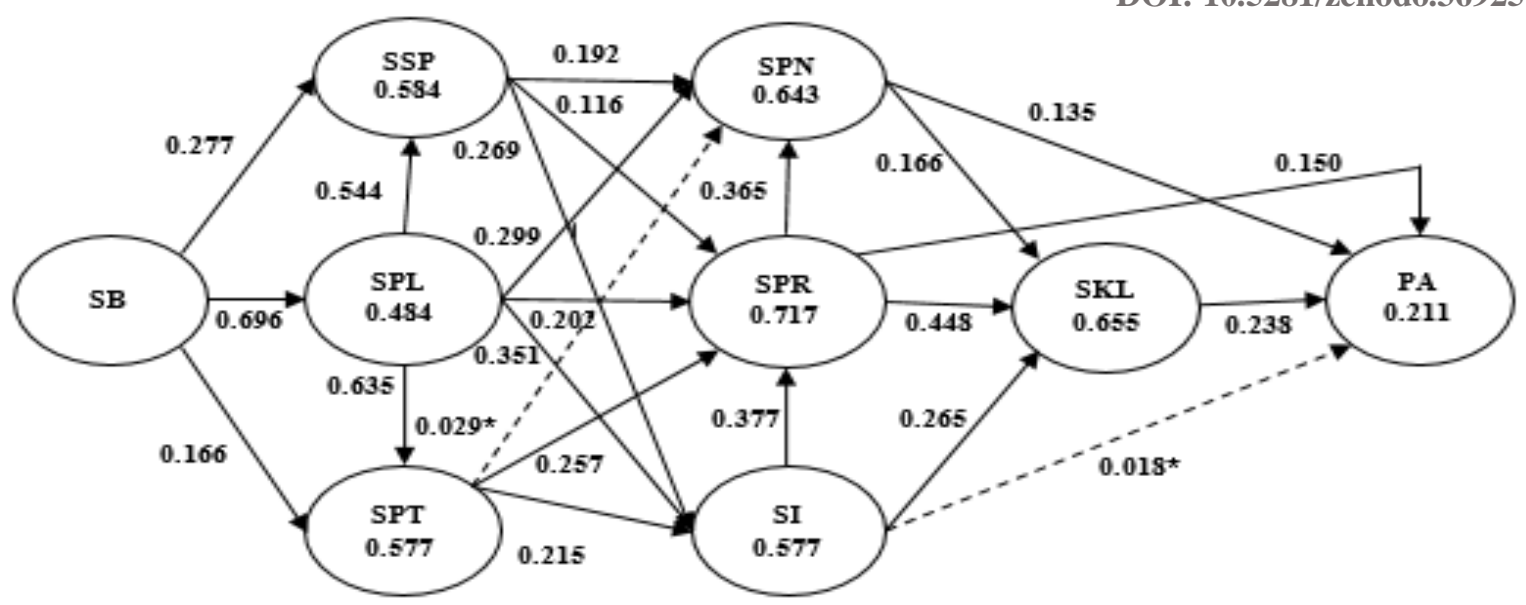

Figure 5: Structural Model 2 Based on the Ministry of National Education and Culture (2012)

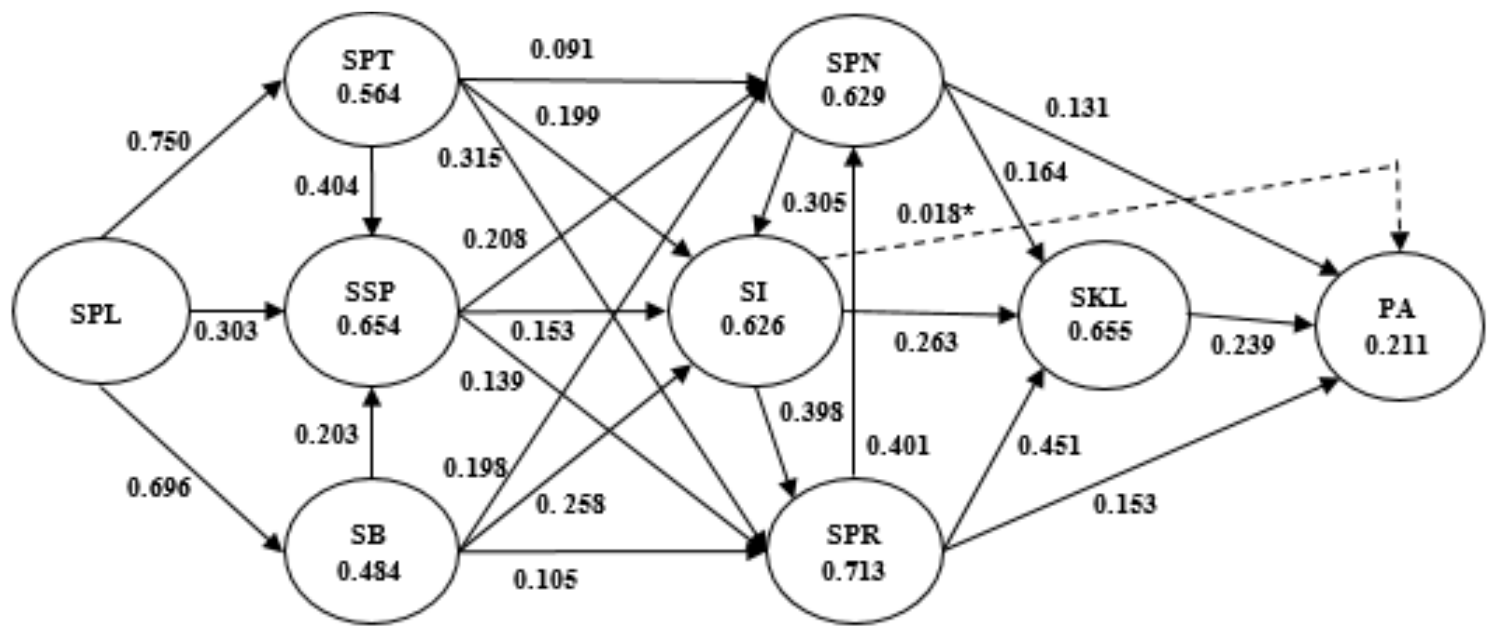

Figure 6: Structural Model 3 Based on the Ministry of National Education and Culture (2017)

\section{Overall Goodness of Fit}

The FIT values generated for model 1, model 2, and model 3 are $0.603,0.623$ and 0.630 . Based on the FIT value, it can be interpreted that the total diversity of all variables that can be explained by each model is $60.3 \%, 62.3 \%$, and $63 \%$. Based on the percentage variety value, it can be concluded that the model published by Ministry of National Education (2017) better describes the variety of data than the other two models.

\section{Conclusion and Recommendations}

In this study, it can be concluded that the model published by the Ministry of Education and Culture (2012) is the best model to describe relationship between 8 national education standards. This model indicates 13 indicators are not valid, namely items 13, 38, 39, 46, 51, 55, 57, 59, 72, 74, 75, 80, and 108. Standard of competency (SKL), standard of process (SPR), and standard of assessment (SPN) have a significant effect on academic performance (PA). 
This research recommends National Accreditation Board to develop and formulate new indicators for accreditation.

\section{References}

[1] [KEMDIKBUD] Kementerian Pendidikan dan Kebudayaan. Pedoman Pemenuhan Standar Nasional Pendidikan pada Sekolah Menengah Pertama (SMP)/Madrasah Tsanawiyah (MTS). Jakarta: Badan Pengembangan Sumberdaya Manusia Pendidikan dan Kebudayaan dan Penjaminan Mutu Pendidikan; 2012.

[2] [KEMDIKNAS dan KEMENAG] Kementerian Pendidikan Nasional dan Kementrian Agama. Sistem Penjaminan Mutu Pendidikan: Panduan Teknis Evaluasi Diri Sekolah (EDS). Jakarta (ID); 2010.

[3] Fornell C, Lacker DF. Evaluating Structural Equation Models with Unobservable Variable and Measurement Error. Journal of Marketing Research. 1981; 18(1):39-50.

[4] Hijrah M, Susetyo B, Sartono B. Structural Equation Modeling of National Standard Education of Vocational High School Using Partial Least Square Path Modeling. IJSRSET. 2018; 4:1418-1422.

[5] Hwang H, Takane Y. Generalized Structured Component Analysis. Psychometrica. 2004; 69(1):8199.

[6] Hwang H, Takane Y. 2014. Generalized Structured Component Analysis: A Component-Based Approach to Structural Equation Modeling. New York: CRC Press.

[7] Ryoo JH, Hwang H. Model Evaluation in Generalized Structured Component Analysis Using Confirmatory Tetrad Analysis. Frontiers in Psychology. 2017; 8:1-10.

[8] Setiawan IA, Susetyo B, Fitrianto A. Application of Generalized Structural Component Analysis to Identify Relation between Accreditation and National Assessment. IJSRSET. 2018; 4:93-97.

[9] Vita D, Susetyo B, Indriyanto B. Generalized Structured Component Analysis (GSCA) for National Education Standards (NES) for Secondary School in Indonesia. Global Journal of Pure and Applied Mathematics. 2015; 11(4):2441-2449.

*Corresponding author.

E-mail address: buset008@yahoo.com 